Article

\title{
Cnicus benedictus Oil as a Raw Material for Biodiesel: Extraction Optimization and Biodiesel Yield
}

\author{
Petronela Lina Matei ${ }^{1}$, Cristina Busuioc ${ }^{1}{ }^{\circledR}$, Niculina Ionescu ${ }^{2}$, Anicuta Stoica-Guzun ${ }^{1}$ and \\ Nicoleta-Aurelia Chira ${ }^{2, *}$ (D) \\ 1 Faculty of Applied Chemistry and Material Science, University POLITEHNICA of Bucharest, \\ 011061 Bucharest, Romania; petro_matei@yahoo.com (P.L.M.); cristina.busuioc@upb.ro (C.B.); \\ stoica.anicuta@gmail.com (A.S.-G.) \\ 2 Laboratory of Plant Multiplication, Plant Breeding and Seed Multiplication Department, \\ National Agricultural Research and Development Institute (NARDI), 915200 Fundulea, Romania; \\ nica@ricic.ro \\ * Correspondence: nicoleta.chira@chimie.upb.ro; Tel.: +40-723-217-507
}

check for updates

Citation: Matei, P.L.; Busuioc, C.; Ionescu, N.; Stoica-Guzun, A.; Chira, N.-A. Cnicus benedictus Oil as a Raw Material for Biodiesel: Extraction Optimization and Biodiesel Yield. Sustainability 2021, 13, 13193.

https://doi.org/10.3390/su132313193

Academic Editor: Shashi Kant Bhatia

Received: 3 November 2021

Accepted: 25 November 2021

Published: 29 November 2021

Publisher's Note: MDPI stays neutral with regard to jurisdictional claims in published maps and institutional affiliations.

Copyright: (c) 2021 by the authors. Licensee MDPI, Basel, Switzerland. This article is an open access article distributed under the terms and conditions of the Creative Commons Attribution (CC BY) license (https:/ / creativecommons.org/licenses/by/ $4.0 /)$.

\begin{abstract}
Cnicus benedictus fruits were used as raw material to extract oil, and the resulting oil was converted into biodiesel. Two extraction methods were tested: batch extraction, and ultrasound assisted extraction. Response surface methodology was considered for the optimization of the process efficiency. The selected key independent variables were temperature, extraction time, and solid/liquid ratio for batch extraction and ultrasound intensity, temperature, and extraction time for the ultrasound assisted extraction, respectively. The optimal working conditions are different for the two extraction techniques, with respect to temperature, solid/liquid ratio, and extraction time, respectively, leading to higher extraction efficiency in the case of the ultrasound-assisted extraction. Cnicus benedictus oil obtained under the optimal extraction conditions was further esterified with methanol under acid catalysis to yield biodiesel. The biodiesel was characterized through ${ }^{1} \mathrm{H}-\mathrm{NMR}$ and the main fuel properties were determined.
\end{abstract}

Keywords: Cnicus benedictus oil; blessed thistle; ultrasound assisted extraction; response surface methodology; Box-Behnken design; biodiesel

\section{Introduction}

Blessed thistle (Cnicus benedictus L.) is a well-known medicinal plant which belongs to the Asteraceae family, and has been used for centuries in traditional medicine due to its complex composition. All of the parts of Cnicus benedictus (CB) are used as extracts, mainly to enhance bile secretion, to stimulate appetite and digestion, mainly due to its high content of cnicin, a sesquiterpene lactone [1-3]. CB extracts also possess antimicrobial, cytotoxic, anti-inflammatory, and wound healing effects [4,5], which may be attributed to the high tannin content, up to $8 \%$ in the whole herb [6]. Recently, CB was reported as an alternative oil crop in central Europe, with fruit yields of approximately $2.0-2.5 \mathrm{t} / \mathrm{ha}$, as well as good oil yields of 500-700 kg/ha. The oil content of CB fruits was reported to range between 23-29.2\% [7]. It is important to mention, based on literature studies, that the main constituent of CB oil is linoleic acid; this oil is also rich in and $\alpha$-tocopherol $[2,7]$. CB is a crop which has demonstrated a great adaptability to different environmental conditions, and it was proposed to be cultivated for restoration of eroded zones [8]. The role of minor crops has been reconsidered in Europe by the scientific community due to the fact that these crops could diversify the agricultural production for medicinal and industrial applications. $\mathrm{CB}$ is one of these crops, and its preservation and cultivation is on the agenda of different European countries [9]. Romania was recognized as offering very good conditions for $C B$ cultivation [7]. In addition, $C B$ oil could be used for biodiesel production. The importance of obtaining biodiesel from new sources of raw materials is a topical issue [10], and CB oil could be regarded as an alternative to other natural sources. 
A recent study conducted in North Dakota (USA) demonstrated that CB has a good productivity in marginal lands, and the biodiesel properties are acceptable for industrial purposes [8]. The importance of extraction methods for vegetal oils and technologies for obtaining biodiesel also draw researchers' attention [11]. For this reason, not only should agronomical studies be continuing, but also the extraction conditions of CB oil should be improved, with the aim of increasing the extraction yield. The oil is extracted from $\mathrm{CB}$ fruits mainly by pressing at $40-50{ }^{\circ} \mathrm{C}$, resulting as a light yellow green to dark yellow oil [7].

Ultrasound-assisted extraction (UAE) is seen as an option to standard solid-liquid extraction, being acknowledged as an effective technique to enhance the extraction yield, especially by a drastic reduction of the extraction time in the case of targeted natural compounds [12,13]. Given its reproducibility, UAE has been used to recover compounds from various vegetal matrices $[14,15]$. Ultrasounds improve the solvent infiltration into the plant material, by displacing the cell walls, hence accelerating the release of targeted substances into the solvent $[16,17]$. Since ultrasounds of vegetal materials interactions are not fully understood at present, new studies are necessary to find the optimal experimental conditions for UAE. Statistical methods such as response surface methodology (RSM) are often used to search for the optimal conditions of a process, particularly if there are several parameters and interactions which could influence the system evolution. By reducing the number of experimental trials which should be carried out to assess the interactions among influencing variables, RSM reduces the efforts and the experimental costs $[18,19]$. The Box-Behnken design (BBD) was chosen in this work as it implies a small number of runs, as compared to other statistical designs [19].

The aims of this study are: (1) characterization of the chemical structure of CB oil (fatty acids profile, technical quality, and nutritional quality indices); (2) presentation of comparative experimental data for batch extraction and UAE of CB oil, using $n$-hexane as a solvent; and (3) synthesis and characterization of biodiesel from CB oil. The effect of process variables for extraction was studied and optimized using BBD. A desirability function was used for the optimization of the extraction in both cases. According to a literature survey, a comparative study between different extraction methods of CB oil at the same time as the synthesis and characterization of biodiesel obtained from CB oil has not yet been reported.

\section{Materials and Methods}

\subsection{Vegetal Material}

Cnicus benedictus fruits were obtained from the National Agricultural Research and Development Institute of Fundulea, Romania (NARDI-Fundulea), located in Calaraşi County (Romania) in 2020, being used as a vegetal material. Solid impurities were manually removed from $\mathrm{CB}$ fruits. The fruits were dried at $50{ }^{\circ} \mathrm{C}$ in a food dehydrator (Tribest Sedona Express SDE-P6280, Anaheim, CA, USA). After drying, the fruits were stored at $4 \pm 1{ }^{\circ} \mathrm{C}$ in sealed plastic bags until oil extraction.

\subsection{Extraction Techniques}

\subsubsection{Soxhlet-Extraction}

The initial oil content in CB fruits was determined using a laboratory Soxhlet extractor and $n$-hexane (Merck, Germany) of analytical reagent grade as a solvent. Approximately $5 \mathrm{~g}$ of ground fruits were weighted and subjected to continuous (Soxhlet) extraction with $100 \mathrm{~mL} n$-hexane for $8 \mathrm{~h}$. The extraction was performed in triplicate. The moisture content of the fruits $(5 \pm 0.02 \%)$ was determined with a thermal balance (OHAUS MB23).

\subsubsection{Batch Extraction}

In a typical experiment, ground $\mathrm{CB}$ fruits were placed into a round bottom flask fitted with a water condenser. A magnetic stirrer operated at $300 \mathrm{rpm}$ with a heating plate, and a temperature controller (PT 1000 temperature sensor) was used to ensure effective contact 
between the phases, and to establish the working temperature. After a predetermined time, the mixture was vacuum filtered and the solvent was removed under low pressure, using a rotary evaporator. The independent variables were chosen after preliminary experiments i.e., extraction time, solid/liquid ratio and working temperature. These values were varied according to BBD.

\subsubsection{Ultrasound Assisted Extraction (UAE)}

UAE was performed with a $500 \mathrm{~W}$ Ultrasonic Processors VCX Series (Sonics \& Materials, Inc., Newtown, CT, USA). Samples of dried and ground CB fruits were placed in a glass vessel close-fitting the US probe top diameter, equipped with a reflux condenser, and operated at different temperatures, extraction times, and amplitudes, according to the experimental design (BBD). For all UAE trials, the solid/liquid ratio was kept at 1/16 $(\mathrm{g} / \mathrm{mL})$.

The schematic flowchart of the methodology is presented in Scheme S1 (Supplementary Material).

\subsection{Analysis of Fatty Acid Profile of CB Oil}

This analysis was carried on according to a previously reported method [20]. CB oil was transesterified with methanol $\left(14 \% \mathrm{BF}_{3}-\mathrm{MeOH}\right.$ solution was used as an acid catalyst) to obtain the corresponding fatty acid methyl esters (FAME) [20,21]. An Agilent 7890B gas chromatograph (Agilent Technologies, USA) equipped with auto sampler, 5975 C VL MSD triple axis MS detector, and a Supelco SP ${ }^{\mathrm{TM}} 2560$ capillary column (100 m length, $0.25 \mathrm{~mm}$ inner diameter, and $0.2 \mu \mathrm{m}$ film thickness) were used for FAME separation and identification. The carrier gas was helium $(1.0 \mathrm{~mL} / \mathrm{min}$, split ratio 1:100) and the oven temperature ranged as follows: $140{ }^{\circ} \mathrm{C}(5 \mathrm{~min}), 140-240{ }^{\circ} \mathrm{C}\left(4^{\circ} \mathrm{C} / \mathrm{min}\right)$, and $240{ }^{\circ} \mathrm{C}$ (20 min). FAME solutions (FAME/ $\mathrm{CH}_{2} \mathrm{Cl}_{2}: 10 \mu \mathrm{L} / 990 \mu \mathrm{L}$ ) were injected, and the fatty acids were identified based on their retention times, as compared against a commercial standard mixture (Supelco ${ }^{\circledR} 37$ Component FAME Mix). The fatty acid profile of CB oil was determined based on the GC peak areas, adjusted by the response factors of the detector; these factors were calculated for each FAME taking methyl oleate as a reference. The response factors were obtained as an average of five injections.

\subsection{Determination of the Oil Quality Indices}

\subsubsection{Peroxide Value (PV)}

$\mathrm{PV}$ was determined by iodometric titration, based on the fact that $\mathrm{I}_{2}$ is stoichiometrically released by hydroperoxides from excess $\mathrm{KI}$. The $\mathrm{I}_{2}$ formed was backtitrated with a standard $\mathrm{Na}_{2} \mathrm{~S}_{2} \mathrm{O}_{3}$ solution in the presence of starch as an indicator [22].

\subsubsection{Free Fatty Acids Value (FFA) and Acid Value (AV)}

FFA was determined by titration of oil dissolved in ethanolic $\mathrm{NaOH}$ solution, using phenolphthalein to observe the color shift. AV was determined from FFA by applying 1.99 as a conversion factor for oleic acid: FFA (\% oleic) $\times 1.99=\mathrm{AV}$ [23].

\subsection{Fruits Morphology}

CB dried fruit morphology was visualized before and after extraction by means of a FEI Quanta Inspect F Scanning Electron Microscope (SEM, FEI Company, Hillsboro, OR, USA). The operating conditions were as follows: secondary electron mode, $30 \mathrm{kV}$ accelerating voltage, $10 \mathrm{~mm}$ working distance. All samples were gold coated by DC magnetron sputtering for $60 \mathrm{~s}$ prior to SEM examination in order to ensure surface conductivity [19].

\subsection{Experimental Design and Statistical Analysis}

Response surface methodology (RSM) using the Box-Behnken design (BBD) was employed to assess the influence of each process variable on the oil extraction yield from CB fruits. RSM, an effective statistical technique, allows for the analysis of individual con- 
tributions and interactions of independent variables on the response, and could accurately describe the global process based on a limited number of runs [19]. BBD, which is one of the most common rotatable models, was preferred for obtaining a polynomial model (second order) to explain the contribution of each process variable on the response (extraction yield of $\mathrm{CB}$ oil). The obtained data were integrated into the following second-order polynomial model according to Equation (1), where $Y$ is the response variable, $\beta_{0}$ is the constant term, $\beta_{i}$ are the linear coefficients, and $\beta_{i i}$ and $\beta_{i j}$ represent the quadratic and interactive coefficients, respectively [19]:

$$
Y=\beta_{0}+\sum \beta_{i} x_{i}+\sum \beta_{i i} x_{i}^{2}+\sum \beta_{i j} x_{i} x_{j}
$$

The STATISTICA 10 software package (Stat Soft Inc., Tulsa, OK, USA) was used for experimental design analysis and data processing. Fisher's F-test was applied to assess the significance of the regression coefficients. The significant terms in the model, returned after regression analysis, were discovered using Pareto analysis of variance (ANOVA) for the responses. Three-dimensional response surface plots were used to illustrate the independent variables interaction [19].

Extraction yield (response) determined using Equation (2), where $M_{o i l}$ is the amount of oil (g), and $M_{d f}$ is the mass of the dried fruits (g):

$$
Y=\frac{M_{\text {oil }}}{M_{d f}} \times 100
$$

For batch extraction, $Y_{1}$ denotes the extraction yield, and for UAE, the corresponding variable is denoted as $Y_{2}$.

The extraction conditions for batch and UAE were optimized using the desirability function, which transforms each response to a desirability value $d_{i}$ between 1 and 0 . The value 1 corresponds to the ideal response value, and 0 to an undesirable response [15].

\section{Box-Behnken Factorial Design for Batch Extraction}

Based on the preliminary experiments, the most important variables and their domain of variation were determined. Table 1 gives the three independent factors designed as $X_{1}$ (temperature), $X_{2}$ (extraction time), and $X_{3}$ (solid/liquid ratio), and their corresponding values for batch extraction of $\mathrm{CB}$ oil. For UAE extraction of $\mathrm{CB}$ fruits oil, three independent variables were designed as $x_{1}$ (temperature), $x_{2}$ (extraction time), and $x_{3}$ (US intensity), their corresponding values being presented also in Table 1.

\begin{tabular}{|c|c|c|c|c|c|c|c|c|c|}
\hline \multirow{2}{*}{$\begin{array}{c}\text { Independent } \\
\text { Variable; } \\
\text { Batch Extraction }\end{array}$} & \multirow{2}{*}{$\begin{array}{l}\text { Coded } \\
\text { Symbol }\end{array}$} & \multicolumn{3}{|c|}{ Level } & \multirow{2}{*}{$\begin{array}{c}\text { Independent } \\
\text { Variable; UAE }\end{array}$} & \multirow{2}{*}{$\begin{array}{l}\text { Coded } \\
\text { Symbol }\end{array}$} & \multicolumn{3}{|c|}{ Level } \\
\hline & & -1 & 0 & 1 & & & -1 & 0 & 1 \\
\hline Temperature $\left({ }^{\circ} \mathrm{C}\right)$ & $X_{1}$ & 25 & 45 & 65 & Temperature $\left({ }^{\circ} \mathrm{C}\right)$ & $x_{1}$ & 30 & 40 & 50 \\
\hline Extraction time (h) & $X_{2}$ & 1 & 2 & 3 & Extraction time (min) & $x_{2}$ & 5 & 10 & 15 \\
\hline $\begin{array}{l}\text { Solid/liquid ratio } \\
\qquad(\mathrm{g} / \mathrm{mL})\end{array}$ & $X_{3}$ & $1 / 8$ & $1 / 12$ & $1 / 16$ & US intensity $\left(\mathrm{W} / \mathrm{cm}^{2}\right)$ & $x_{3}$ & 5.06 & 9.64 & 13.77 \\
\hline
\end{tabular}

Table 1. Independent variables and their levels in the response surface for batch extraction and for UAE of CB fruits oil.

\subsection{Biodiesel Synthesis from CB Fruit Oil and Its Characterization}

Biodiesel was synthesized based on a two-step procedure: saponification, followed by methylation of alkali soaps with some modifications [21]. A measure of $50 \mathrm{~mL} \mathrm{CB}$ oil $(50 \mathrm{mmol})$ and $50 \mathrm{~mL} \mathrm{NaOH}$ in methanol solution $(0.1 \mathrm{~N})$ were placed in a double-necked $500 \mathrm{~mL}$ round bottom flask fitted with a condenser, magnetic stirrer, and dropping funnel, and refluxed for $30 \mathrm{~min} .\left(64{ }^{\circ} \mathrm{C}, 300 \mathrm{rpm}\right)$. After completion of saponification reaction (the mixture became homogeneous), $5 \mathrm{~mL} \mathrm{H}_{2} \mathrm{SO}_{4} 98 \%$ solution $(\mathrm{d}=1.98 \mathrm{~g} / \mathrm{mL}, 100 \mathrm{mmol}$ ) 
dissolved in $50 \mathrm{~mL}$ was added dropwise through a dropping funnel, and the mixture was maintained at reflux for $30 \mathrm{~min}$. The reaction mixture was cooled to $25^{\circ} \mathrm{C}$ and its separation into two phases (methyl esters and glycerol) indicated that the methylation had occurred. Cold water $\left(100 \mathrm{~mL}\right.$, approx. $\left.4{ }^{\circ} \mathrm{C}\right)$ was added, and the flask contents were transferred into a $500 \mathrm{~mL}$ separatory funnel. FAME were extracted three times with $50 \mathrm{~mL}$ methylene chloride $(\mathrm{d}=1.38 \mathrm{~g} / \mathrm{mL})$ portions. The combined organic extracts (lower layers) were washed with cold water until reaching a neutral $\mathrm{pH}$, then dried on anhydrous $\mathrm{MgSO}_{4}$, and separated through centrifugation. Methylene chloride was removed with a rotary evaporator. Biodiesel was obtained ( $89.4 \%$ yield) as a light-yellow oil, and was characterized through ${ }^{1} \mathrm{H}-\mathrm{NMR}$.

\section{Results and Discussions}

\subsection{CB Fruits Oil Characterization}

The CB fruit oil content was determined to be $33.20 \pm 0.68 \%$ (reported to the dried fruits, Soxhlet method). Compared to the few literature data available on the oil content of $C B$ fruits, this value is higher than any other previously reported, ranging between 24-29.2\% [7]. Indeed, the cultivation area provides favourable pedo-climatic conditions for CB growth; however, 2020 was particularly favorable, with higher seed quality and seed production compared to previous years also registered for other Asteraceae oil plants. Since we could only find one paper reporting the fatty acids profile of CB oil [7], and nothing has been said about the oil free fatty acids content, methylation was carried out under acidic conditions using $\mathrm{BF}_{3}-\mathrm{CH}_{3} \mathrm{OH}$ complex as a catalyst, to ensure total methylation of the fatty acids from triacylglycerols, as well as from FFA [21]. The composition of the oil samples using different extraction techniques (Soxhlet, batch and UAE) was determined through gas-chromatography, and the results are displayed in Table 2. A characteristic chromatogram of CB oil obtained for Soxhlet extraction in n-hexane is presented in Figure 1. Table 2 shows the $\mathrm{CB}$ oil characterization as obtained by various extraction techniques.

Table 2. CB oil characterization as obtained by various extraction techniques.

\begin{tabular}{|c|c|c|c|c|c|}
\hline \multirow{2}{*}{ No. } & \multirow{2}{*}{ Fatty acid } & \multirow{2}{*}{$\begin{array}{l}\text { Lipid } \\
\text { Number }\end{array}$} & \multicolumn{3}{|c|}{$\begin{array}{c}\text { Fatty acids profile * } \\
\text { of Cnicus benedictus fruit oil (molar \%) }\end{array}$} \\
\hline & & & $\begin{array}{l}\text { Soxhlet extraction } \\
\text { (n-hexane, } 8 \text { h) }\end{array}$ & $\begin{array}{l}\text { Batch extraction } \\
\left(65^{\circ} \mathrm{C}, 3 \mathrm{~h}\right)\end{array}$ & $\begin{array}{c}\mathrm{UAE} \\
\left(50^{\circ} \mathrm{C}, 15 \mathrm{~min}, 13.77 \mathrm{~W} / \mathrm{cm}^{2}\right)\end{array}$ \\
\hline 1 & Palmitic & $\mathrm{C} 16: 0$ & $5.31 \pm 0.19$ & $5.40 \pm 0.15$ & $5.50 \pm 0.08$ \\
\hline 2 & Stearic & C18:0 & $2.03 \pm 0.09$ & $2.10 \pm 0.08$ & $2.10 \pm 0.04$ \\
\hline 3 & Oleic & C18:1 & $18.96 \pm 0.48$ & $19.02 \pm 0.42$ & $19.01 \pm 0.39$ \\
\hline 4 & Linoleic & C18:2 & $73.69 \pm 0.87$ & $73.48 \pm 0.79$ & $73.39 \pm 0.82$ \\
\hline \multicolumn{6}{|c|}{ Technical oil quality indices * } \\
\hline \multicolumn{3}{|c|}{$\mathrm{AV}$ (mg KOH/g oil) } & $2.46 \pm 0.28$ & $2.38 \pm 0.16$ & $2.44 \pm 0.12$ \\
\hline \multicolumn{3}{|c|}{ FFA (as \% oleic acid) } & $1.24 \pm 0.08$ & $1.20 \pm 0.05$ & $1.23 \pm 0.04$ \\
\hline \multicolumn{3}{|c|}{ IV ( $\mathrm{g} \mathrm{I}_{2} / 100 \mathrm{~g}$ oil $)$} & $143.2 \pm 0.8$ & $142.6 \pm 0.6$ & $142.8 \pm 0.8$ \\
\hline \multicolumn{3}{|c|}{$\mathrm{SV}$ (mg KOH/g oil) } & $191 \pm 1$ & $192 \pm 1$ & $191 \pm 1$ \\
\hline \multicolumn{3}{|c|}{ PV (meq. active oxygen $/ \mathrm{kg}$ of oil) } & $2.5 \pm 0.1^{* *}$ & $2.4 \pm 0.02 * *$ & $2.7 \pm 0.1^{* *}$ \\
\hline \multicolumn{3}{|c|}{ Total fat $\ddagger$ (g/100 g fruits) } & 33.20 㧊 & & \\
\hline
\end{tabular}

* Mean values (three replicates) \pm s.d.; $\ddagger$ Reported to the dry seeds; $¥ \ddagger$ Determined for CB oil obtained through Soxhlet extraction. ${ }^{* *}$ Represent significant differences (one-way ANOVA and Duncan's test, $p<0.05$ ).

The fatty acid profile of $\mathrm{CB}$ oil is similar regardless of the extraction technique (Table 2). The most abundant fatty acid (accounting up to $73.69 \%$ ) is linoleic acid (C18:2), considered as an essential fatty acid. It is the starting point for the biosynthesis of a series of $\omega-6$ fatty acids, eventually leading to arachidonic acid (C20:4) [20,24]. CB oil also contains important amounts (up to 19.02\%) of oleic acid (C18:1). Relatively low levels (ranging 7.34-7.60\%) of saturated fatty acids (palmitic $\mathrm{C} 16: 0$ and stearic $\mathrm{C} 18: 0$ ) complete the fatty acids profile of the oil. Similar composition results (linoleic acid 71.80-75.0\%, oleic acid 16.95-19.7\%, 
palmitic acid 5.95-6.67\%, and stearic acid 2.72-3.29\%) have recently been reported for CB cultivated in Germany [7]. No statistically significant differences were found between different extraction techniques regarding oil composition (one-way ANOVA).

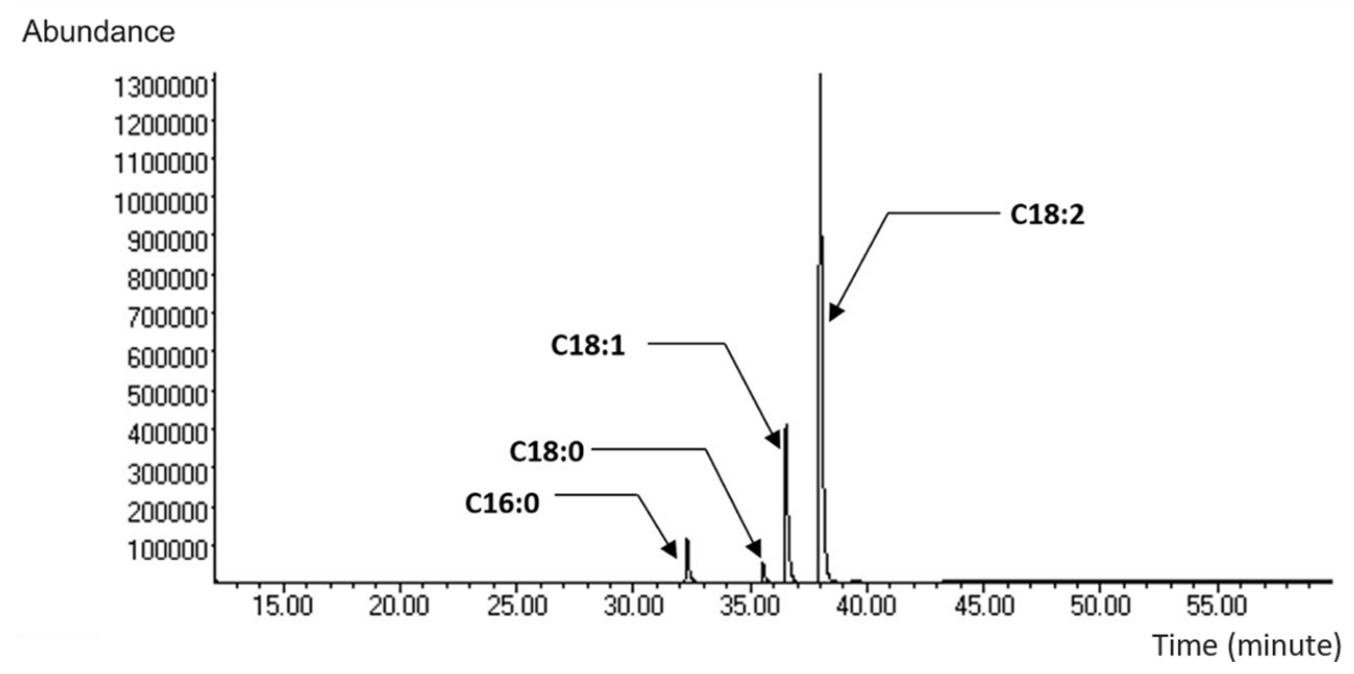

Figure 1. Cnicus benedictus fruit oil (Soxhlet extraction, $n$-hexane, $8 \mathrm{~h}$ ) chromatogram.

With respect to the technical quality indices, CB oil has a relatively high IV (143.2 g $\mathrm{I}_{2} / 100 \mathrm{~g}$ oil), due to its high content of C18:2, and an SV of $191 \mathrm{mg} \mathrm{KOH} / \mathrm{g}$ oil, which confirms the mainly $\mathrm{C} 18$ fatty acids oil composition.

It has been reported in the literature [25] that UAE may promote oxidative degradation of the biologically active compounds. This could constitute a considerable disadvantage of the UAE technique, restricting its utility. In this study, the evaluation of the contribution of ultrasounds on the lipid degradation during UAE was formulated based on specific oil quality indices (i.e., peroxide value PV, acid value AV, and the free fatty acids FFA). PV, $\mathrm{AV}$ and FFA were determined on three samples (one for each extraction technique, taking the longest exposure time, temperature, and process intensity). According to Table 2, PV presents statistically significant differences $(p<0.05)$ among the samples obtained through Soxhlet, batch extraction, and UAE. However, no major peroxidation process occurred during these experiments; only in the case of UAE did PV slightly increase from 2.5 meq. active oxygen $/ \mathrm{kg}$ of oil (Soxhlet) to 2.7 meq. active oxygen $/ \mathrm{kg}$ of oil (UAE), confirming that ultrasounds may increase lipid peroxidation. On the other hand, PV values were low, despite the high levels of PUFA; a possible explanation is that peroxidation was prevented or limited by three factors: (1) CB oil is naturally protected against peroxidation by its high levels of tocopherols [7]; (2) short exposure time (max. $15 \mathrm{~min}$.); and (3) temperature was kept at max. $50{ }^{\circ} \mathrm{C}$. No important triacylglycerols hydrolysis occurred during extractions, with AV and FFA having close values (2.38-2.46 mg KOH/g oil and $1.20-1.24 \%$ expressed as oleic acid, respectively).

\subsection{Extraction Yield of CB Oil Batch Extraction Optimized by RSM}

Table 3 presents the experimental design for batch extraction and UAE of CB oil. 
Table 3. BBD settings of independent variables and the experimental and predicted values for CB oil extraction efficiency for batch extraction $\left(Y_{1}\right)$ and extraction efficiency $\left(Y_{2}\right)$ for UAE, respectively.

\begin{tabular}{|c|c|c|c|c|c|c|c|}
\hline \multirow{2}{*}{ Run } & \multirow{2}{*}{$\begin{array}{l}X_{1} \\
x_{1}\end{array}$} & \multirow{2}{*}{$\begin{array}{l}X_{2} \\
x_{2}\end{array}$} & \multirow{2}{*}{$\begin{array}{l}X_{2} \\
x_{3}\end{array}$} & \multicolumn{2}{|c|}{$Y_{1}(\%)$} & \multicolumn{2}{|c|}{$Y_{2}(\%)$} \\
\hline & & & & Experimental & Predicted & Experimental & Predicted \\
\hline 1 & -1 & -1 & 0 & 23.02 & 23.11 & 29.48 & 29.20 \\
\hline 2 & -1 & 0 & -1 & 23.12 & 23.13 & 28.51 & 28.44 \\
\hline 3 & -1 & 0 & 1 & 23.62 & 23.62 & 28.60 & 28.77 \\
\hline 4 & -1 & 1 & 0 & 23.88 & 23.77 & 31.07 & 31.24 \\
\hline 5 & 0 & -1 & -1 & 23.22 & 23.11 & 28.56 & 28.90 \\
\hline 6 & 0 & -1 & 1 & 24.38 & 24.27 & 29.35 & 29.45 \\
\hline 7 & 0 & 0 & 0 & 24.62 & 24.72 & 28.00 & 28.37 \\
\hline 8 & 0 & 1 & -1 & 24.02 & 24.12 & 30.44 & 30.33 \\
\hline 9 & 0 & 1 & 1 & 24.84 & 24.94 & 31.88 & 31.53 \\
\hline 10 & 1 & -1 & 0 & 24.44 & 24.55 & 30.98 & 30.80 \\
\hline 11 & 1 & 0 & -1 & 24.26 & 24.25 & 29.39 & 29.21 \\
\hline 12 & 1 & 0 & 1 & 25.75 & 25.74 & 30.56 & 30.62 \\
\hline 13 & 1 & 1 & 0 & 25.68 & 25.58 & 32.00 & 32.27 \\
\hline 14 & 0 & 0 & 0 & 25.00 & 24.72 & 28.00 & 28.37 \\
\hline 15 & 0 & 0 & 0 & 24.50 & 24.72 & 28.20 & 28.37 \\
\hline 16 & 0 & 0 & 0 & 24.80 & 24.72 & 27.99 & 28.37 \\
\hline 17 & 0 & 0 & 0 & 24.68 & 24.72 & 28.10 & 28.37 \\
\hline
\end{tabular}

The expression of $Y_{1}$ (extraction yield for batch extraction) in terms of coded variables is reflected as a second order model in Equation (3):

$$
\begin{gathered}
Y_{1}=24.72+0.811 X_{1}-0.196 X_{1}^{2}+0.420 X_{2}-0.268 X_{2}^{2}+0.496 X_{3}-0.336 X_{3}^{2} \\
+0.095 X_{1} X_{2}+0.247 X_{1} X_{3}-0.085 X_{2} X_{3}
\end{gathered}
$$

$F$-test, $p$-value and ANOVA were applied to verify the statistical significance of the regression model for the response surface second order model (Table 4).

Table 4. ANOVA test for $Y_{1}$ response function (extraction yield) for batch extraction.

\begin{tabular}{cccccc}
\hline Term & $\begin{array}{c}\text { Sum of } \\
\text { Squares }\end{array}$ & DF & $\begin{array}{c}\text { Mean } \\
\text { Square }\end{array}$ & F-Value & $p$-Value \\
\hline Model & 10.00263 & 9 & 1.1114 & 33.34328 & $0.000063^{\text {a }}$ \\
$X_{1}$ & 5.26501 & 1 & 5.265013 & 145.4423 & $0.000271^{\text {a }}$ \\
$X_{2}$ & 1.41120 & 1 & 1.411200 & 38.9834 & $0.003354^{\text {a }}$ \\
$X_{3}$ & 1.97011 & 1 & 1.970112 & 54.4230 & $0.001800^{\text {a }}$ \\
$X_{1}^{2}$ & 0.16216 & 1 & 0.162164 & 4.4797 & 0.101739 \\
$X_{2}^{2}$ & 0.30411 & 1 & 0.304112 & 8.4009 & $0.044188^{\text {a }}$ \\
$X_{3}^{2}$ & 0.47606 & 1 & 0.476059 & 13.1508 & $0.022231^{\text {a }}$ \\
$X_{1} X_{2}$ & 0.03610 & 1 & 0.036100 & 0.9972 & 0.374495 \\
$X_{1} X_{3}$ & 0.24502 & 1 & 0.245025 & 6.7686 & 0.059943 \\
$X_{2} X_{3}$ & 0.02890 & 1 & 0.028900 & 0.7983 & 0.422089 \\
Lack of Fit & 0.08852 & 3 & 0.029508 & 0.8151 & 0.548753 \\
Pure Error & 0.14480 & 4 & 0.036200 & & \\
Total SS & 10.23595 & 16 & & & \\
$R^{2}=0.977$ & Adj $R^{2}=0.947$ & & $C V=3.28$ & & \\
a Values are significant at $p<0.05$. & & & &
\end{tabular}

It can be observed from Table 4 that the quadratic model is highly significant, with a very high $F$ value of 33.343 , and a low $p$-value $<0.000063$. These values represent proof that the obtained model could accurately describe the relationship between the extraction yield and the independent variables for CB oil extraction, in the case of batch extraction [19].

The high values of $R^{2}(0.977)$ and of $\operatorname{Adj} R^{2}(0.947)$ suggest good correlation between experimental and predicted values. Based on the value of Adj $R^{2}$, only $5.3 \%$ of the total variation could not be explained by the proposed model. The coefficient of variance $(\mathrm{CV})$ 
is less than $5 \%$, which supports the good fit of the mathematical model. Using the $p$-value ( $95 \%$ confidence level) to examine the significance of the model coefficients, the effects lower than 0.05 were considered significant. Consequently, it is evident that the extraction yield is influenced by the linear coefficients $\left(X_{1}, X_{2}\right.$, and $\left.X_{3}\right)$ and by the quadratic terms $X_{2}{ }^{2}$ and $X_{3}{ }^{2}$, the $p$-values being less than 0.5 for all these terms.

The simplified fitted quadratic model obtained by neglecting the non-significant terms ( $p$-values $>0.05)$ in Equation (3) is described by Equation (4):

$$
Y_{1}=24.72+0.811 X_{1}-0.268 X_{2}{ }^{2}+0.420 X_{2}+0.496 X_{3}-0.336 X_{3}{ }^{2}
$$

The influence of extraction parameters on the $\mathrm{CB}$ oil extraction efficiency were visualized using the response surface plots. From Figure 2a, it can be seen that both temperature and solid/liquid ratio exhibit a significant effect upon extraction yield of CB oil; this parameter is increasing with the increase of the two variables. Figure $2 b$ represents the response surface plot of solid/liquid ratio and time. It can be observed that the solid/liquid ratio has a more pronounced influence upon extraction yield in comparison with time. Figure $2 \mathrm{c}$ represents the response surface plot of the two independent variables extraction time and temperature. It is evident that both variables are influencing the extraction yield, the maximum being attended for a high temperature and a long extraction time.

a)
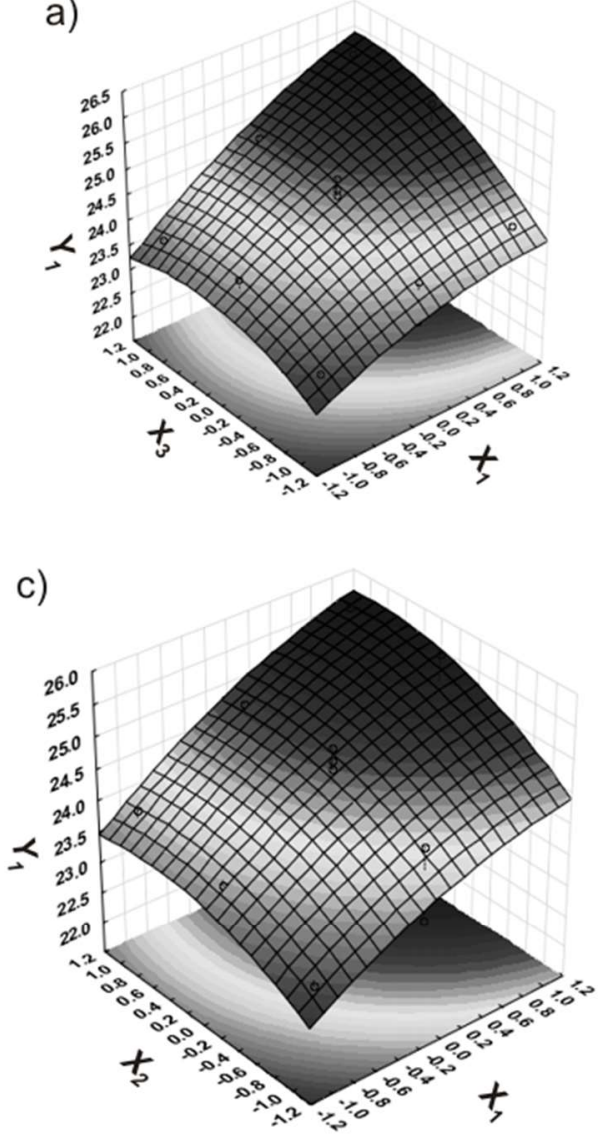

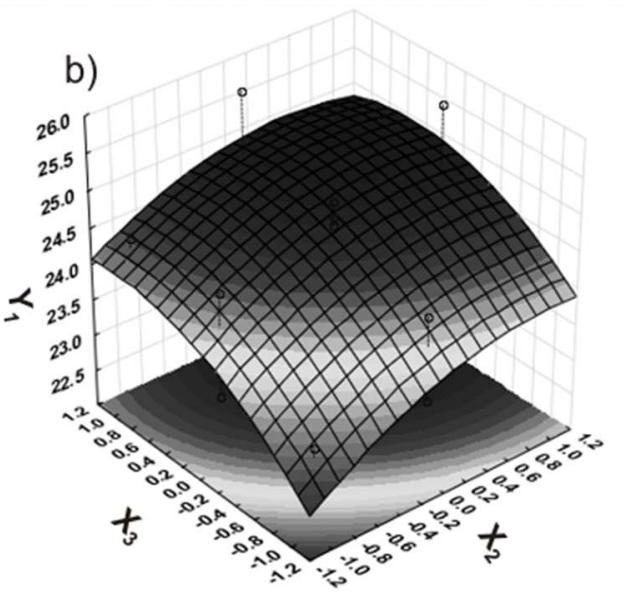

d)

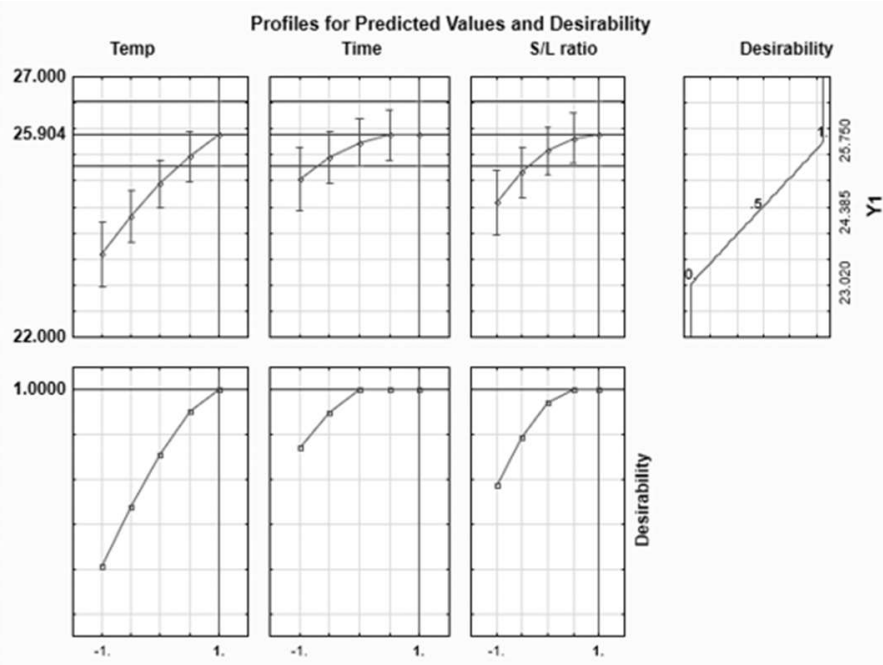

Figure 2. (a-c) response surface plots for the influence of independent variables (coded symbols) of batch extraction on CB extraction yield, (d) desirability profile for optimal CB oil batch extraction parameters. 


\subsection{Desirability Optimization for CB Oil for Batch Extraction}

Extraction efficiency of $\mathrm{CB}$ oil (batch extraction) was optimised by using the desirability function [26]. The values of optimal conditions were 1 for all variables: temperature $\left(65^{\circ} \mathrm{C}\right)$, time $(3 \mathrm{~h})$, and solid liquid ratio $(1 / 16)$. The optimum value of $Y_{1}$ was found to be $25.75 \%$ in agreement with the experimental value determined in the same experimental conditions $\left(Y_{1 \exp }=26.00 \pm 0.28 \%\right)$. Profiles for predicted oil extraction efficiency and the desirability level of the influencing factors for optimal conditions in the case of batch extraction are presented in Figure 2d.

The morphology of CB fruits was examined through SEM before and after extraction using different techniques: (a) Soxhlet extraction, and (b) batch extraction.

In Figure $3 \mathrm{a}, \mathrm{b}$ a compact structure of the raw vegetal material is observed before extraction. After Soxhlet extraction (Figure 3c), the vegetal material appears more depleted as compared with batch extraction, which is in agreement with the lower extraction yield in the case of the batch approach (Figure 3d).
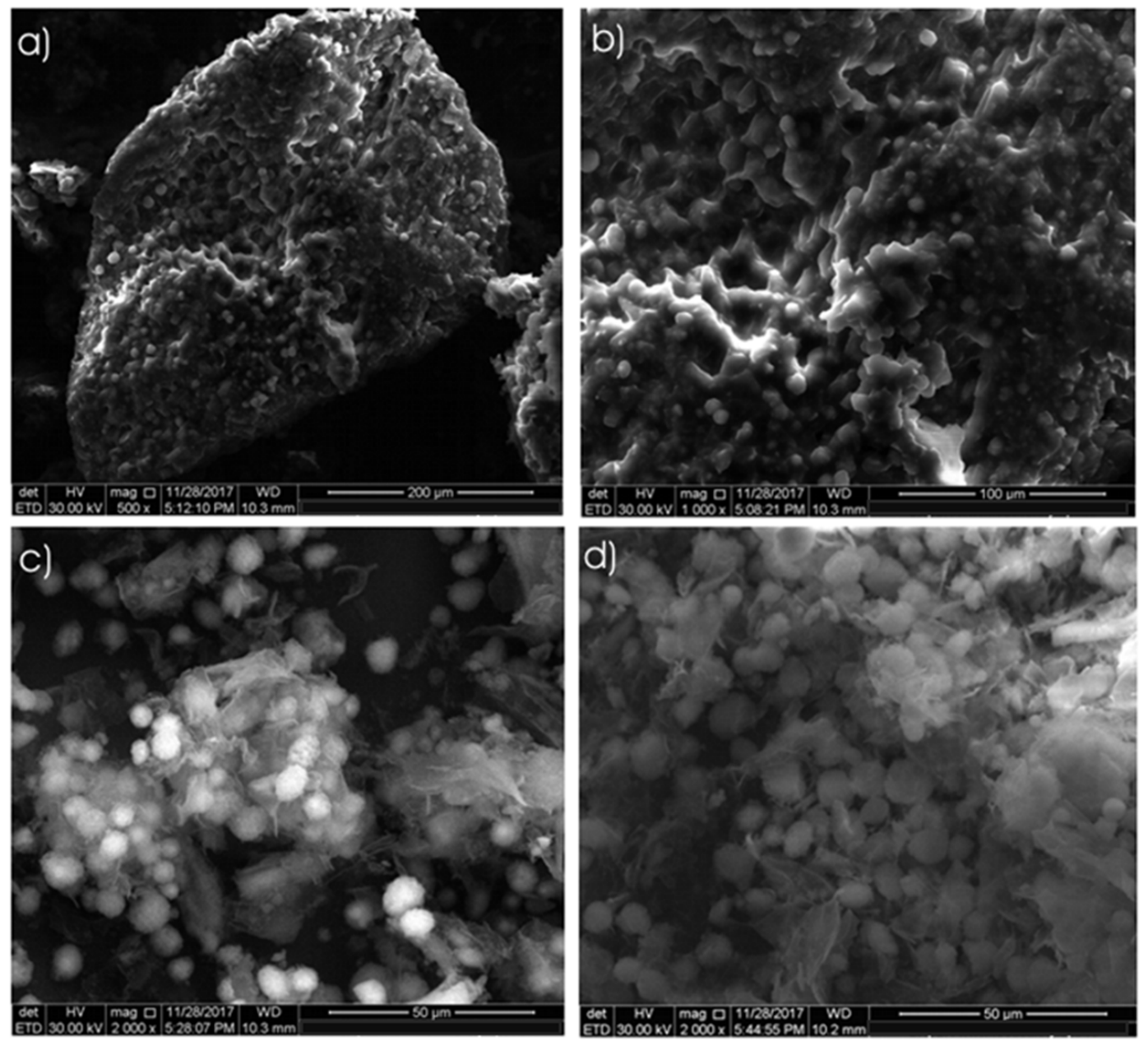

Figure 3. SEM images of the CB grinded fruits: (a,b) before extraction at different magnitudes; (c) after Soxhlet extraction, and (d) after batch extraction.

\subsection{Extraction Yield of CB Oil UAE Optimized by RSM}

Equation (5) presents the second order model for $Y_{2}$ (extraction yield for $\mathrm{CB}$ oil for UAE) in terms of coded variables:

$$
\begin{gathered}
Y_{2}=24.418+0.677 x_{1}+0.787 x_{1}^{2}+0.886 x_{2}+1.664 x_{2}^{2}+0.418 x_{3}+0.0347 x_{3}{ }^{2} \\
-0.220 x_{1} x_{2}+0.245 x_{1} x_{3}+0.222 x_{2} x_{3}
\end{gathered}
$$


$F$-test, $p$-value, and ANOVA were applied to verify the statistical significance of the regression model for the response surface second order model (Table 5).

Table 5. ANOVA test for $Y_{2}$ response function (extraction yield) for UAE.

\begin{tabular}{cccccc}
\hline Term & Sum of Squares & DF & $\begin{array}{c}\text { Mean } \\
\text { Square }\end{array}$ & F-Value & $p$-Value \\
\hline Model & 27.01459 & 9 & 0.138265 & 21.70919 & $0.000261^{\mathrm{a}}$ \\
$x_{1}$ & 3.67205 & 1 & 3.67205 & 21.08919 & $0.010089^{\mathrm{a}}$ \\
$x_{2}$ & 6.28351 & 1 & 6.28351 & 36.08725 & $0.003865^{\mathrm{a}}$ \\
$x_{3}$ & 1.40281 & 1 & 1.40281 & 8.05658 & $0.046943^{\mathrm{a}}$ \\
$x_{1}{ }^{2}$ & 2.60953 & 1 & 2.60953 & 14.98694 & $0.017974^{\mathrm{a}}$ \\
$x_{2}{ }^{2}$ & 11.66902 & 1 & 11.66902 & 67.01712 & $0.001213^{\mathrm{a}}$ \\
$x_{3}$ & 0.00508 & 1 & 0.00508 & 0.02920 & 0.872612 \\
$x_{1} x_{2}$ & 0.19360 & 1 & 0.19360 & 1.11188 & 0.351153 \\
$x_{1} x_{3}$ & 0.24010 & 1 & 0.24010 & 1.37893 & 0.305422 \\
$x_{2} x_{3}$ & 0.19802 & 1 & 0.19802 & 1.13729 & 0.346316 \\
Lack of Fit & 0.27138 & 3 & 0.09046 & 0.51952 & 0.691268 \\
Pure Error & 0.69648 & 4 & 0.17412 & & \\
Total SS & 27.98245 & 16 & & & \\
$R^{2}=0.9654$ & Adj $R^{2}=0.9209$ & & $C V=4.5 \%$ & & \\
\hline a Values are significant at $p<0.05$ & & &
\end{tabular}

The ANOVA analysis from Table 5 revealed that the model is statistically significant, with a very high $F$ value of 21.709 at $95 \%$ confidence level. Since $R^{2}$ and adjusted $R^{2}$ are higher than 0.90 , we can conclude that the experimental results agree with the predicted values, a conclusion which is also supported by the results presented in Table 2 . Only $7.91 \%$ of the total system variation could not be explained by the suggested model. The coefficient of variation $(\mathrm{CV})$ has a low value $(<5 \%)$, suggesting a high accuracy of the experiment. Neglection of non-significant terms ( $p$-values $>0.05$ ) in Equation (5) leads to a simplified fitted quadratic model, i.e., Equation (6):

$$
Y_{2}=24.418+0.677 x_{1}+0.787 x_{1}^{2}+0.886 x_{2}+1.664 x_{2}{ }^{2}+0.418 x_{3}
$$

Figure 4 presents the response surface plot of extraction yield for UAE $\left(Y_{2}\right)$ as a function of time, temperature, and US intensity. From Figure $4 a, b$ it can be seen that the extraction time and temperature have a more pronounced influence upon extraction yield, in comparison with US intensity. The increase of the extraction time and temperature favours $\mathrm{CB}$ oil extraction in the case of UAE.

\subsection{Desirability Optimization for CB Oil for UAE}

Extraction efficiency of $\mathrm{CB}$ oil (UAE) was also optimized by means of the desirability function. The values of optimal conditions were 1 for all variables: temperature $\left(50{ }^{\circ} \mathrm{C}\right)$, time (15 $\mathrm{min})$, and US intensity $\left(13.77 \mathrm{~W} / \mathrm{cm}^{2}\right)$. The solid/liquid ratio was kept constant at $1 / 16 \mathrm{~g} / \mathrm{mL}$, as in the batch extraction experiment. The optimum value of $Y_{2}$ was found to be $32 \%$ in correlation with the experimental value, determined under similar working conditions $\left(Y_{2 \exp }=31.1 \pm 0.44 \%\right)$. Profiles for predicted oil extraction yield and the desirability level for the influencing factors for optimal conditions of UAE extraction are presented in Figure 4d. CB fruits were analysed through SEM after UAE, and the images are presented in Figure 5. If we compare the images of the CB fruits after UAE with those presented in Figure 3c,d, it is evident that the US produces oil depletion in the vegetal matrix. 
a)

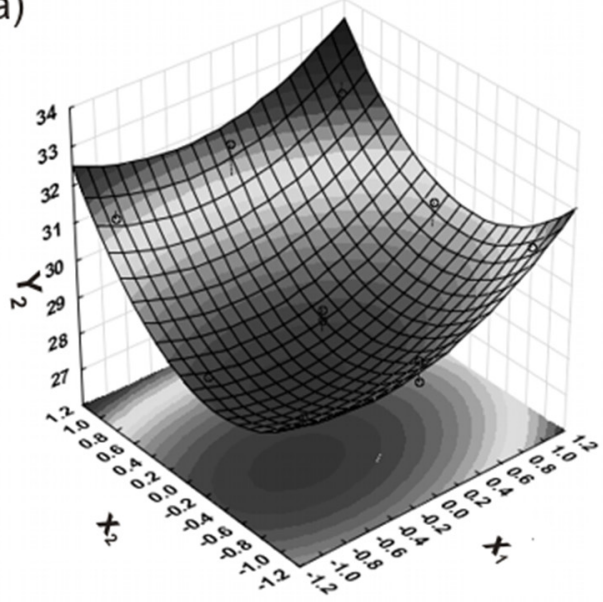

c)

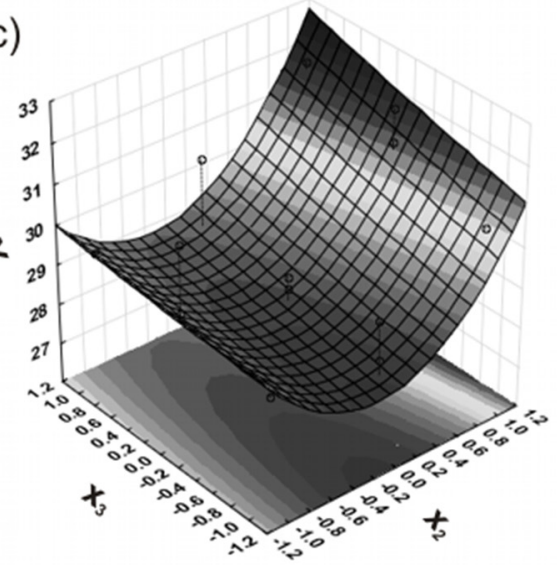

b)

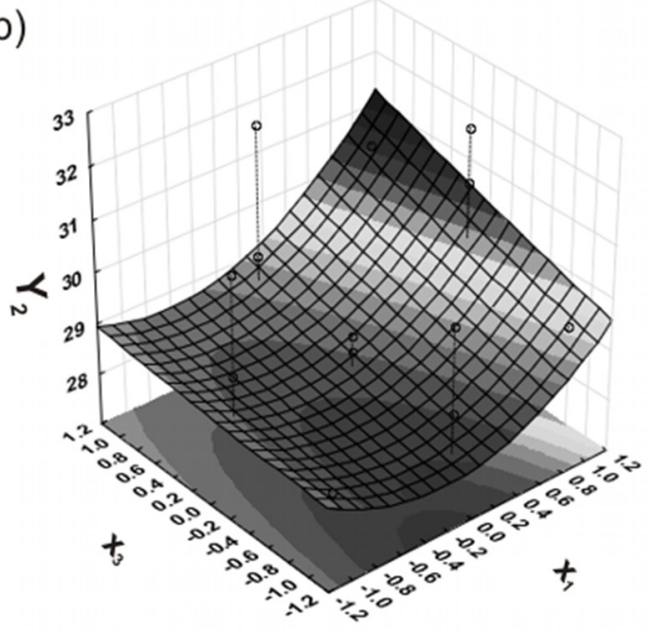

d)

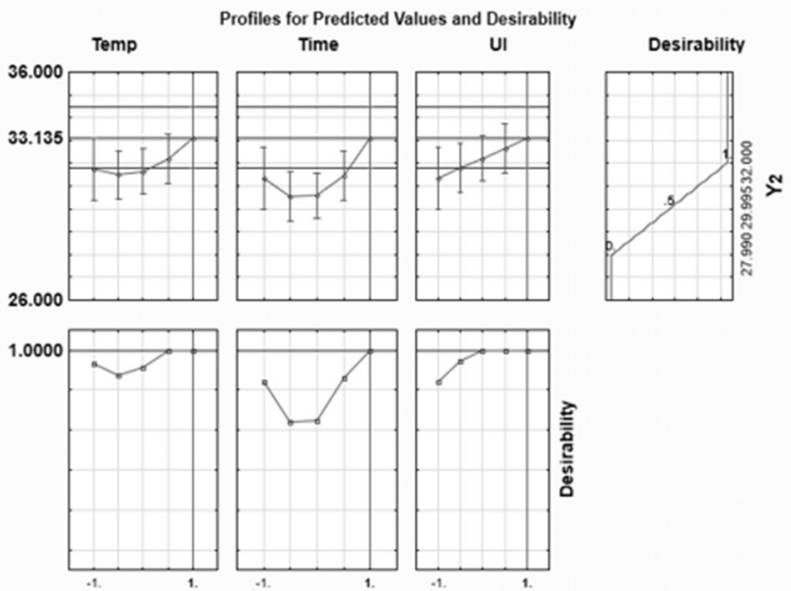

Figure 4. Response surface plots for the contribution of process variables of UAE on CB extraction yield: (a) extraction time/temperature; (b) US intensity (UI) /temperature, (c) US intensity (UI)/extraction time, expressed as coded symbols, (d) desirability profile for optimal UAE extraction parameters.
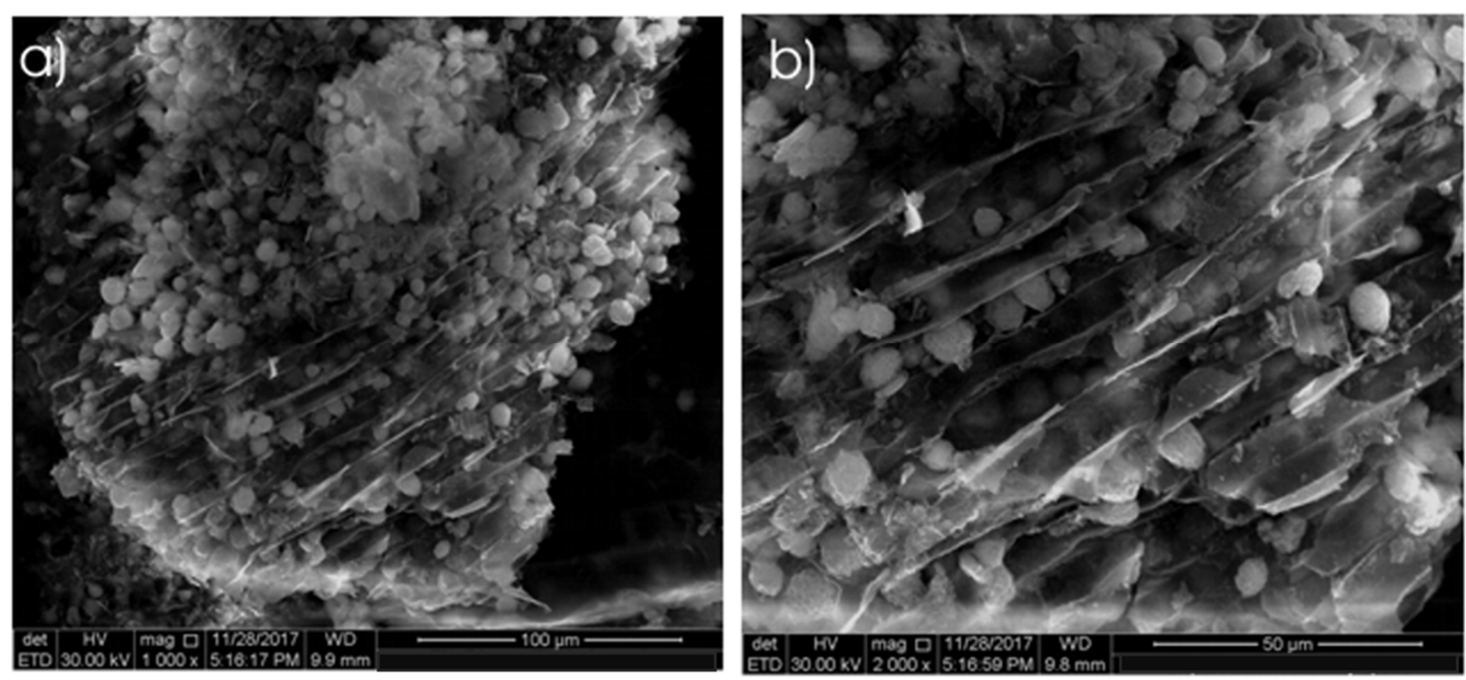

Figure 5. SEM images at different magnitudes of the CB grinded fruits after UAE. (a) $1000 \times$ (b) $2000 \times$. 


\subsection{Synthesis of Biodiesel from CB Oil and Its Properties}

Biodiesel was synthesized under acidic catalysis, based on a two-step procedure involving saponification followed by methylation of alkali soaps, according to Scheme 1 .

$$
\text { Saponification }
$$

\begin{tabular}{|c|c|c|c|c|c|}
\hline $\mathrm{CH}_{2}-\mathrm{O}-\mathrm{CO}-\mathrm{R}_{1}$ & & & $\mathrm{CH}_{2}-\mathrm{OH}$ & & $\mathrm{R}_{1}-\mathrm{COONa}$ \\
\hline CH-O-CO-R 2 & $+3 \mathrm{NaOH}$ & $64^{\circ} \mathrm{C}$ & $\mathrm{CH}-\mathrm{OH}$ & + & $\mathrm{R}_{2}-\mathrm{COONa}$ \\
\hline $\mathrm{CH}_{2}-\mathrm{O}-\mathrm{CO}-\mathrm{R}_{3}$ & & & $\mathrm{CH}_{2}-\mathrm{OH}$ & & $\mathrm{R}_{3}-\mathrm{COO}$ \\
\hline CB oil & & & Glycerol & & $\mathrm{Na}$ \\
\hline
\end{tabular}

Methylation

\begin{tabular}{|c|c|c|c|c|c|}
\hline \multicolumn{2}{|l|}{$\mathrm{R}_{1}-\mathrm{COONa}$} & \multicolumn{4}{|c|}{$\mathrm{R}_{1}-\mathrm{COOCH}_{3}$} \\
\hline $\mathrm{R}_{2}-\mathrm{COONa}$ & $+3 \mathrm{CH}_{3} \mathrm{OH}$ & $\mathrm{H}_{2} \mathrm{SO}_{4}$ & $\mathrm{R}_{2}-\mathrm{COOCH}_{3}$ & + & $3 \mathrm{NaOH}$ \\
\hline $\mathrm{R}_{3}-\mathrm{COONa}$ & & $64^{\circ} \mathrm{C}$ & $\mathrm{R}_{3}-\mathrm{COOCH}_{3}$ & & \\
\hline Na soaps & & & Biodiesel ( & & \\
\hline
\end{tabular}

Scheme 1. Synthesis of biodiesel from CB oil.

The stacked ${ }^{1} \mathrm{H}-\mathrm{NMR}$ spectra of CB oil and biodiesel are presented in Figure 6, and the assignment of ${ }^{1} \mathrm{H}$-NMR resonances is presented in Table 6 .

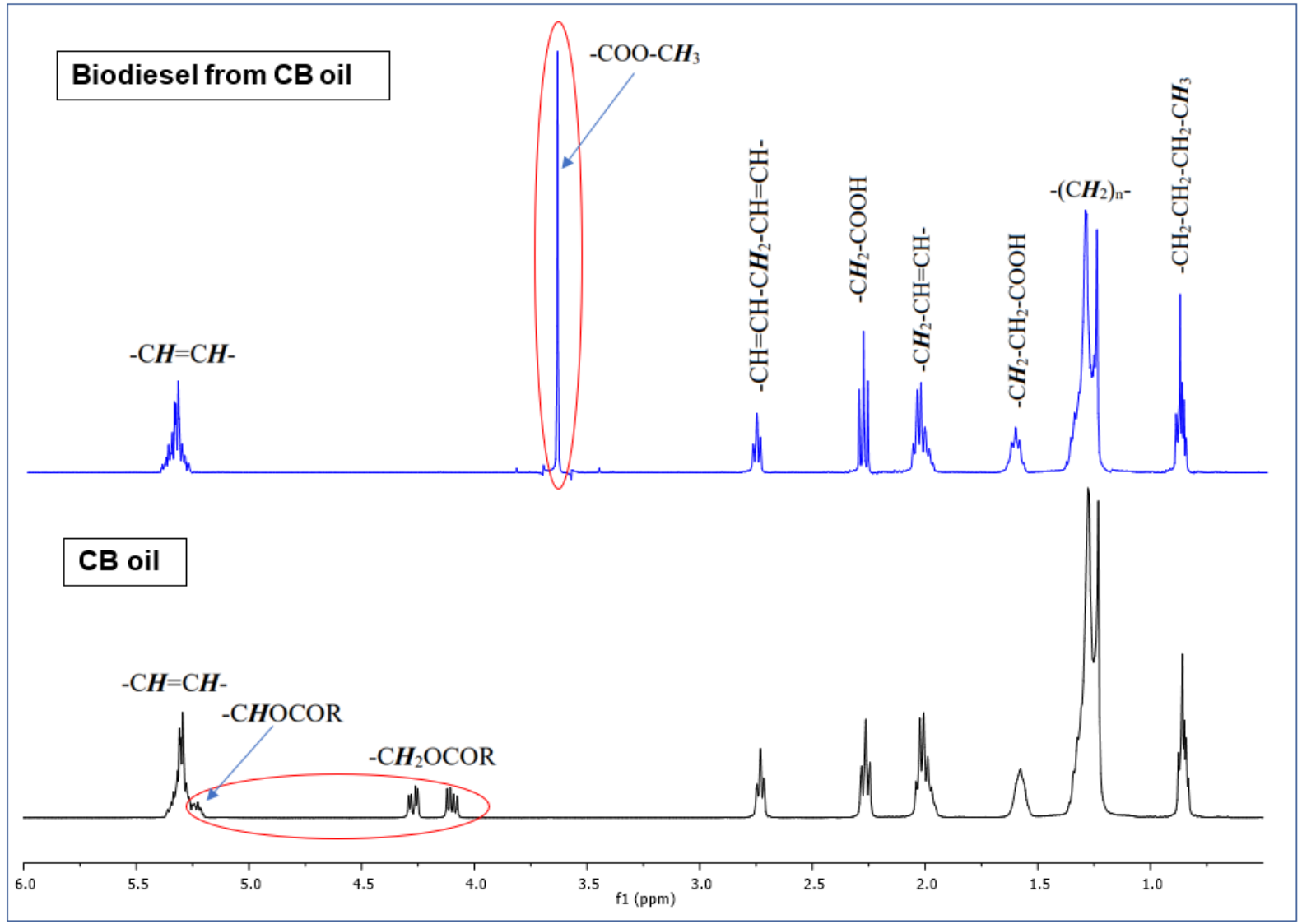

Figure 6. Stacked ${ }^{1} \mathrm{H}-\mathrm{NMR}$ spectra of $\mathrm{CB}$ oil and biodiesel from $\mathrm{CB}$ oil. 
Table 6. Chemical shifts and assignment of ${ }^{1} \mathrm{H}-\mathrm{NMR}$ resonances for $\mathrm{CB}$ oil and CB biodiesel [27].

\begin{tabular}{|c|c|c|c|}
\hline No. & $\mathrm{d}(\mathrm{ppm})$ & Proton & Compound \\
\hline 1 & 0.85 & $-\mathrm{CH}_{2}-\mathrm{CH}_{2}-\mathrm{CH}_{2}-\mathrm{CH}_{3}$ & all acids in $\mathrm{CB}$ oil \\
\hline 2 & 1.24 & $-\left(\mathrm{CH}_{2}\right)_{n^{-}}$ & all fatty acids \\
\hline 3 & 1.64 & $-\mathrm{CH}_{2}-\mathrm{CH}_{2}-\mathrm{COO}-$ & all fatty acids \\
\hline 4 & 2.02 & $-\mathrm{CH}_{2}-\mathrm{CH}=\mathrm{CH}-$ & $\mathrm{C} 18: 2$ and $\mathrm{C} 18: 1$ \\
\hline 5 & 2.26 & $-\mathrm{CH}_{2}-\mathrm{COO}-$ & all fatty acids \\
\hline 6 & 2.76 & $-\mathrm{CH}=\mathrm{CH}-\mathrm{CH}_{2}-\mathrm{CH}=\mathrm{CH}-$ & linoleic acid (C18:2) \\
\hline 7 & 3.60 & $-\mathrm{COO}-\mathrm{CH}_{3}$ & methyl ester moiety \\
\hline 8 & 4.19 & $-\mathrm{CH}_{2} \mathrm{OCOR}$ & $\begin{array}{c}H \text { in the } s n-1 / 3 \text { position of the } \\
\text { glycerol moiety }\end{array}$ \\
\hline 9 & 5.20 & -CHOCOR & $\begin{array}{c}\mathrm{H} \text { in the } s n-2 \text { position of the } \\
\text { glycerol moiety }\end{array}$ \\
\hline 10 & 5.29 & $-\mathrm{CH}=\mathrm{CH}-$ & $\mathrm{C} 18: 2$ and $\mathrm{C} 18: 1$ \\
\hline
\end{tabular}

The ${ }^{1} \mathrm{H}-\mathrm{NMR}$ spectra of both $\mathrm{CB}$ oil and $\mathrm{CB}$ fatty acid methyl esters (biodiesel) display the same resonances for the hydrocarbon chain, and differ only with respect to the ester moiety. As expected, the signals associated with unsaturation (i.e., allylic, bis-allylic, and directly bonded to $s p^{2} \mathrm{C}$ in the double bonds) have high intensities, in correlation with the fatty acid composition (the main constituent being linoleic acid, $\omega-6$ ). The completion of the transesterification reaction of $\mathrm{CB}$ oil to obtain biodiesel is proven in the ${ }^{1} \mathrm{H}-\mathrm{NMR}$ spectrum, by the resonance at $3.60 \mathrm{ppm}$ (singlet), assigned to the new methyl group from the ester moiety. At the same time-as expected-the resonances at 4.19 and 5.20 from the glycerol ester moiety are absent in the spectrum of the reaction product, confirming that the acyl groups have detached from the glycerol backbone. Biodiesel properties are shown in Table 7.

Table 7. Biodiesel properties.

\begin{tabular}{|c|c|c|c|}
\hline No. & Fatty acid & Lipid number & $\begin{array}{c}\text { Fatty acids profile * } \\
\text { (molar \%) }\end{array}$ \\
\hline 1. & Palmitic & C16:0 & $5.42 \pm 0.12$ \\
\hline 2. & Stearic & C18:0 & $2.18 \pm 0.07$ \\
\hline 3. & Oleic & $\mathrm{C} 18: 1$ & $19.11 \pm 0.32$ \\
\hline 4. & Linoleic & C18:2 & $73.29 \pm 0.83$ \\
\hline \multicolumn{4}{|c|}{ Technical quality indices } \\
\hline \multicolumn{3}{|c|}{ Mean molar weight $(\mathrm{g} / \mathrm{mol}) * *$} & $293.6 \pm 1.2$ \\
\hline \multicolumn{3}{|c|}{ Specific gravity, at $15^{\circ} \mathrm{C}\left(\mathrm{kg} / \mathrm{m}^{3}\right)$} & $0.874 \pm 0.003$ \\
\hline \multicolumn{3}{|c|}{$\mathrm{AV}$ (mg KOH/g biodiesel) } & $0.42 \pm 0.07$ \\
\hline \multicolumn{3}{|c|}{ IV ( $\mathrm{g} \mathrm{I}_{2} / 100 \mathrm{~g}$ biodiesel $) * *$} & $142.5 \pm 2.3$ \\
\hline \multicolumn{3}{|c|}{$\mathrm{SV}(\mathrm{mg} \mathrm{KOH} / \mathrm{g}$ biodiesel $) * *$} & $191.2 \pm 1.9$ \\
\hline \multicolumn{3}{|c|}{$\mathrm{CN}$} & $53.1 \pm 0.9$ \\
\hline \multicolumn{3}{|c|}{ Kinematic viscosity, at $40{ }^{\circ} \mathrm{C}\left(\mathrm{mm}^{2} / \mathrm{s}\right)$} & $3.1 \pm 0.9$ \\
\hline \multicolumn{3}{|c|}{$\mathrm{CP}\left({ }^{\circ} \mathrm{C}\right)$} & $-2.1 \pm 0.2$ \\
\hline \multicolumn{3}{|c|}{$\mathrm{PP}\left({ }^{\circ} \mathrm{C}\right)$} & $-9.1 \pm 0.2$ \\
\hline \multicolumn{3}{|c|}{$\mathrm{HHV}(\mathrm{MJ} / \mathrm{Kg})$} & $39.91 \pm 0.63$ \\
\hline
\end{tabular}

${ }^{*}$ Mean values $\pm \mathrm{sd}$ (three replicates); ${ }^{* *}$ Determined from the GC data: mean molar weight, iodine value (IV) and saponification value (SV) according to [28], cetane number (CN) according to [29], kinematic viscosity, and higher heating value (HHV) according to [30], and cloud point (CP) and pour point (PP) according to [31].

The mean acidity value obtained of $0.42 \mathrm{mg} \mathrm{KOH} / \mathrm{g}$ biodiesel conforms with the maximum of $0.5 \mathrm{mg} \mathrm{KOH} / \mathrm{g}$ admitted by the ASTM D664 specifications for biodiesel [32]. Ghiasy-Oskoee et al. [8] reported higher AV values ranging from 2.3 to $3.5 \mathrm{mg} \mathrm{KOH} / \mathrm{g}$ for biodiesel from $\mathrm{CBO}$, which were not compliant with standard recommendations. A possible explanation may regard the biodiesel synthesis, which, in their case, was the classical methylation procedure under alkaline catalysis; under alkaline conditions, the free fatty acids remain unmethylated [21]. On the other hand, the transesterification 
reported in the present paper involves the conversion of CB oil into FAME as a two-step synthesis. In the first step, both the triacylglycerols and free fatty acids are converted into Na carboxylates. The second step-methylation-is carried on under acidic catalysis, allowing for the methylation of all carboxylate species. Consequently, AV of biodiesel is considerably lower than in the case of the alkaline esterification. Iodine value (IV) of biodiesel reflects the amount of unsaturated fatty acyl chains. The IV (142 $\mathrm{g} \mathrm{I}_{2} / 100 \mathrm{~g}$ biodiesel) is due to the large amount of di-unsaturated acyl chains from linoleic moiety. The saponification value (SV, $191.2 \mathrm{mg} \mathrm{KOH} / \mathrm{g}$ biodiesel) globally reflects the fatty acyl chain length, with C18 acids accounting for more than $94 \%$. The cetane number $(\mathrm{CN})$ of 53.1 is compliant with the recommendations of the European regulations (EN 14214, European Committee for Standardization), indicating a good ignition quality of the fuel. This value is slightly lower than 54.5 as reported by Ghiasy-Oskoee et al. [8] for biodiesel from CBO, due to the higher amount of linoleic acid (73.29\% in the present case compared to $64.93 \%$, as previously reported). According to Giakoumis and Sarakatsanis [29], the CN of biodiesel depends on the fatty acid composition, with unsaturated fatty acids contributing to the decrease of $\mathrm{CN}$.

Cloud point $(\mathrm{CP}$, the temperature at which FAME crystallization begins) and pour point (PP, the lowest temperature at which the fuel still flows-below this point the fuel does not flow) [31] were found to be $-2.1^{\circ} \mathrm{C}$ and $-9.1^{\circ} \mathrm{C}$, respectively, characterizing the low temperature flow characteristics of biodiesel. The low values are due to the low amounts of palmitic acid methyl ester, which has the highest melting point of all methyl ester species present in CB biodiesel. CP and PP should be taken into account when operating diesel engines in temperature climate regions during winter periods to avoid clogging fuel pipes and filters in diesel devices [31].

The high heating value (HHV) is an important characteristic of fuels, defined as the heat released through the complete combustion of $1 \mathrm{~kg}$ of fuel. The HHV of CB biodiesel was $39.91 \mathrm{MJ} / \mathrm{kg}$, which agrees with the HHV reported for sunflower FAME, which have fatty acid composition comparable to CB biodiesel [30].

\section{Conclusions}

Cnicus benedictus fruits have proven as a rich source of oil, with high amounts of C18:2 (>73\%). An experimental study of CB oil extraction was performed using two extraction techniques: batch extraction, and UAE. The extraction process was optimized using an experimental statistical design. UAE resulted in a higher extraction yield of oil from CB fruits and a shorter extraction time as compared with batch extraction. The optimized value for $\mathrm{UAE}$ offers mild conditions which prevents oil degradation (i.e., $50^{\circ} \mathrm{C}$ for $15 \mathrm{~min}$., $1 / 16 \mathrm{~g} / \mathrm{mL}$ solid/liquid ratio, and $13.77 \mathrm{~W} / \mathrm{cm}^{2}$ US intensity), allowing for $31.1 \%$ CB oil yield. On a laboratory scale, the highest oil yield obtained through ultrasound assisted extraction (31.1\%) seems only slightly higher than previously reported yield (24-29.2\%). However, in our opinion, this difference becomes relevant for the field production (in terms of $\mathrm{kg} / \mathrm{ha}$ ). CB oil was converted to the corresponding fatty acid methyl esters, which were further assessed for fuel characteristics. Results indicate that the obtained CB biodiesel complies with biodiesel regulations, suggesting the plant as an alternative raw material for biodiesel production. Further research should focus on the evaluation and low input improvement of Cnicus benedictus crops under unfavorable environments, as well as the evaluation of $\mathrm{CB}$ fuel behavior in diesel engines.

Supplementary Materials: The following are available online at https:/ /www.mdpi.com/article/10 $.3390 /$ su132313193/s1, Scheme S1: Experimental flowchart.

Author Contributions: Conceptualization, A.S.-G. and N.-A.C.; methodology, P.L.M. and N.I.; software, A.S.-G.; validation, P.L.M., N.-A.C. and C.B.; investigation, P.L.M., N.I., C.B. and N.-A.C.; resources, N.I. and N.-A.C.; writing-original draft preparation, P.L.M.; writing-review and editing, A.S.-G. and N.-A.C. All authors have read and agreed to the published version of the manuscript. 
Funding: This research received no external funding. The APC was funded by the University POLITEHNICA of Bucharest through “Engineer in Europe" project, identified by no. 140/GP/19.04.2021, through the Romanian Ministry of Education fund for special situations financing.

Acknowledgments: The authors gratefully acknowledge Marta Stroescu for fruitful discussions and suggestions regarding the optimization of oil extraction, and Steluţa Radu from NARDI Fundulea for kindly providing the first batch of CB fruits.

Conflicts of Interest: The authors declare no conflict of interest. The funders had no role in the design of the study; in the collection, analyses, or interpretation of data; in the writing of the manuscript, or in the decision to publish the results.

\section{References}

1. Ghiasy-Oskoee, M.; Agha Alikhani, M.; Sefidkon, F.; Mokhtassi-Bidgoli, A.; Ayyari, M. Blessed thistle agronomic and phytochemical response to nitrogen and plant density. Ind. Crops Prod. 2018, 122, 566-573. [CrossRef]

2. Al-Snafi, A.E. The Constituents and Pharmacology of Cnicus Benedictus-A Review. Pharm. Chem. J. 2016, 3, $129-135$.

3. Paun, G.; Neagu, E.; Albu, C.; Radu, G.L. Inhibitory potential of some Romanian medicinal plants against enzymes linked to neurodegenerative diseases and their antioxidant activity. Pharmacogn. Mag. 2015, 11 (Suppl. 1), S110-S116. [PubMed]

4. Szabó, I.; Pallag, A.; Bidar, C.F. The antimicrobial activity of the Cnicus benedictus L. extracts. An. Univ. Din Oradea Fasc. Biol. 2009, Tom XVI 1, 126-128.

5. Djamila, C.; Akym, A.; Faiza, M.; Chahinez, B.; Nacer-bey, N. Anatomical, phytochemical and pharmacological studies of roots of Cnicus benedictus L. Int. J. Med. Plant Res. 2013, 2, 204-208.

6. Maier, M.; Oelbermann, A.-L.; Renner, M.; Weidner, E. Screening of European medicinal herbs on their tannin content-New potential tanning agents for the leather industry. Ind. Crops Prod. 2017, 99, 19-26. [CrossRef]

7. Horn, G.; Kupfer, A.; Rademacher, A.; Kluge, H.; Kalbitz, J.; Eißner, H.; Drager, B. Cnicus benedictus as a potential low input oil crop. Eur. J. Lipid Sci. Technol. 2015, 117, 561-566. [CrossRef]

8. Ghiasy-Oskoee, M.; Hatterman-Valenti, H.; Monono, E.; Agha Alikhani, M. Blessed thistle a promising species on North Dakota, USA marginal lands: Agronomic productivity, oil properties and biodiesel potential. Ecol. Eng. 2020, 155, 105908. [CrossRef]

9. Baričevič, D.; Zupancic, A. Conservation of genetic resources of medicinal and aromatic plants in Europe. Rep. Netw. Coord. Group Minor Crop. 1999, 16, 16-19.

10. Supriyanto, E.; Sentanuhady, J.; Dwiputra, A.; Permana, A.; Muflikhun, M.A. The Recent Progress of Natural Sources and Manufacturing Process of Biodiesel: A Review. Sustainability 2021, 13, 5599. [CrossRef]

11. Zulqarnain; Ayoub, M.; Yusoff, M.H.M.; Nazir, M.H.; Zahid, I.; Ameen, M.; Sher, F.; Floresyona, D.; Budi Nursanto, E. A ComprehensiveReview on Oil Extraction and Biodiesel Production Technologies. Sustainability 2021, 13, 788. [CrossRef]

12. Chemat, F.; Rombaut, N.; Sicaire, A.-G.; Meullemiestre, A.; Fabiano-Tixier, A.-S.; Abert-Vian, M. Ultrasound assisted extraction of food and natural products. Mechanisms, techniques, combinations, protocols and applications. A review. Ultrason. Sonochem. 2017, 34, 540-560.

13. Pandey, A.; Belwal, T.; Chandra Sekar, K.; Bhatt, I.D.; Rawal, R.S. Optimization of ultrasonic-assisted extraction (UAE) of phenolics and antioxidant compounds from rhizomes of Rheum moorcroftianum using response surface methodology (RSM). Ind. Crops Prod. 2018, 119, 218-225. [CrossRef]

14. Nour, V.; Trandafir, I.; Cosmulescu, S. Optimization of ultrasound-assisted hydroalcoholic extraction of phenolic compounds from walnut leaves using response surface methodology. Pharm. Biol. 2016, 54, 2176-2187. [CrossRef] [PubMed]

15. Chanioti, S.; Tzia, C. Optimization of ultrasound-assisted extraction of oil from olive pomace using response surface technology: Oil recovery, unsaponifiable matter, total phenol content and antioxidant activity. LWT-Food Sci. Technol. 2017, 79, 178-189. [CrossRef]

16. Baiano, A. Recovery of Biomolecules from Food Wastes-A Review. Molecules 2014, 19, 14821-14842. [CrossRef]

17. Vinatoru, M.; Mason, T.J.; Calinescu, I. Ultrasonically assisted extraction (UAE) and microwave assisted extraction (MAE) of functional compounds from plant materials. TrAC-Trend Anal. Chem. 2017, 97, 159-178. [CrossRef]

18. Liu, Y.; Wei, S.; Liao, M. Optimization of ultrasonic extraction of phenolic compounds from Euryale ferox seed shells using response surface methodology. Ind. Crops Prod. 2013, 49, 837-843. [CrossRef]

19. Komartin, R.S.; Stroescu, M.; Chira, N.; Stan, R.; Stoica-Guzun, A. Optimization of oil extraction from Lallemantia iberica seeds using ultrasound-assisted extraction. J. Food Meas. Charact. 2021, 15, 2010-2020. [CrossRef]

20. Isopencu, G.; Stroescu, M.; Brosteanu, A.; Chira, N.; Pârvulescu, O.C.; Busuioc, C.; Stoica-Guzun, A. Optimization of ultrasound and microwave assisted oil extraction from sea buckthorn seeds by response surface methodology. J. Food Proc. Eng. 2019, 42, e12947. [CrossRef]

21. Li, Y.; Watkins, B.A. Analysis of Fatty Acids in Food Lipids in Current Protocols in Food Analytical Chemistry; Wrolstad, R.E., Ed.; John Wiley \& Sons, Inc.: New York, NY, USA, 2001; Protocol D1.2.1-D1.2.15.

22. Pegg, R.B. Measurement of primary lipid oxidation products. In Handbook of Food Analytical Chemistry; Wrolstad, R.E., Acree, T.E., Decker, E.A., Penner, M.H., Reid, D.S., Schwartz, S.J., Shoemaker, C.F., Smith, D.M., Sporns, P., Eds.; John Wiley \& Sons, Inc.: Hoboken, NY, USA, 2004; pp. 531-564. 
23. American Oil Chemists' Society. AOCS Official Method Ca5a-40. Free Fatty Acid; A.O.C.S.: Champaign, IL, USA, 1993.

24. Wanten, G.J.; Calder, P.C. Immune modulation by parenteral lipid emulsions. Am. J. Clin. Nutr. 2007, 85, 1171-1184. [CrossRef] [PubMed]

25. Pingret, D.; Fabiano-Tixier, A.-S.; Chemat, F. Degradation during application of ultrasound in food processing: A review. Food Control 2013, 31, 593-606. [CrossRef]

26. Candioti, L.V.; De Zan, M.M.; Cámara, M.S.; Goicoechea, H.C. Experimental design and multiple response optimization. Using the desirability function in analytical methods development. Talanta 2014, 124, 123-128. [CrossRef] [PubMed]

27. Knothe, G.; Kenar, J.A. Determination of the fatty acid profile by ${ }^{1}$ H-NMR Spectroscopy. Eur. J. Lipid Sci. Technol. 2004, 106, 88-96. [CrossRef]

28. Chira, N.; Todaşcă, C.; Nicolescu, A.; Păunescu, G.; Roşca, S. Determination of the technical quality indices of vegetable oils by modern physical techniques. UPB Sci. Bull. Ser. B 2009, 71, 3-12.

29. Giakoumis, E.G.; Sarakatsanis, C.K. A Comparative Assessment of Biodiesel Cetane Number Predictive Correlations Based on Fatty Acid Composition. Energies 2019, 12, 422. [CrossRef]

30. Ramírez-Verduzco, L.F.; Rodríguez-Rodríguez, J.E.; del Rayo Jaramillo-Jacob, A. Predicting cetane number, kinematic viscosity, density and higher heating value of biodiesel from its fatty acid methyl ester composition. Fuel 2012, 91, 102-111. [CrossRef]

31. Sarin, A.; Arora, R.; Singh, N.P.; Sarin, R.; Malhotra, R.K.; Kundu, K. Effect of blends of Palm-Jatropha-Pongamia biodiesels on cloud point and pour point. Energy 2009, 34, 2016-2021. [CrossRef]

32. ASTM (American Society for Testing and Materials). Standard Specification for Biodiesel Fuel Blend Stock (B100) for Distillate Fuels; Designation D 6751-09; ASTM: West Conshohocken, PA, USA, 2019. 